\title{
PENGARUH BUDAYA ORGANISASI TERHADAP KINERJA PEGAWAI PADA DINAS SOSIAL PROVINSI MALUKU
}

\section{Montgomery Warbal, Bernard C. Renyut, Selvia F.G. Renyut}

Sekolah Tinggi Ilmu Administrasi (STIA) Trinitas Ambon, Maluku, Indonesia

Email: montywarbal@gmail.com, bernardrenyut@gmail.com,

selviarenyut14@gmail.com

\begin{abstract}
Abstrak
Tujuan dari penelitian ini adalah untuk mengetahui dan menganalisa tentang pengaruh budaya organisasi terhadap kinerja pegawai di Dinas Sosial Provinsi Maluku. Metode yang digunakan dalam penelitian ini adalah metode penelitian assosiatif dengan menggunakan teknik observasi, wawancara, kuesioner, dan studi pustaka kepada 77 orang responden.

Berdasarkan hasil analisa dengan menggunakan rumus korelasi product moment, data diperoleh bahwa korelasi antara Budaya Organisasi $(X)$ terhadap Kinerja Pegawai (Y) sebesar 0,435 terdapat hubungan yang sedang karena berada pada rentang 0,400 - 0,599. dan uji tingkat signifikannya terlihat bahwa t-hitung lebih besar dari t-tabel $(4,185>1,671)$ berarti bahwa ada pengaruh yang signifikan antara budaya organisasi terhadap kinerja pegawai. Sedangkan koefisien Determinan (R2) pengaruh variabel bebas terhadap perubahan variabel terikat adalah $18,9 \%$, sedangkan $81,1 \%$ sisanya dipengaruhi oleh variabel lain selain variabel budaya organisasi yang tidak masuk dalam penelitian ini.
\end{abstract}

Kata Kunci: budaya organisasi, kinerja pegawai

\section{Abstract}

The purpose of this study was to determine and analyze the influence of organizational culture on employee performance at the Maluku Provincial Social Service. The method used in this study is associative research method using observation, interviews, questionnaires, and literature studies to 77 respondents.

Based on the results of the analysis using the product moment correlation formula, the data shows that the correlation between Organizational Culture $(X)$ and Employee Performance $(Y)$ is 0.435 , there is a moderate relationship because it is in the range $0.400-0.599$. and the significance level test shows that the t-count is greater than the t-table $(4.185>1.671)$ meaning that there is a significant influence between organizational culture on employee performance. While the coefficient of Determinant (R2) the influence of independent variables on changes in the dependent variable is $18.9 \%$, while the remaining $81.1 \%$ is influenced by variables other than organizational culture variables that are not included in this study. 
Keywords: organizational culture, employee performance

\section{Pendahuluan}

Organisasi saat ini sangat berkembang dengan sangat pesat, kita dapat melihat perkembangannya dari sistem yang ada pada sebuah organisasi yang berdiri pada masa kini. Perkembangan dan perubahan pada organisasi harus dilakukan demi berlangsungnya kegiatan organisasi yang lebih baik dan lebih bersahabat dengan lingkungan sekitar organisasi yang berdiri di tengah-tengah masyarakat. Dengan demikian kelak anggota maupun pemimpin suatu organisasi akan menjadi individu yang baik terhadap kawan, keluarga, dan juga masyarakat walaupun sudah tidak ada dalam organisasi lagi, karena sudah terbiasa bekerja sama sebelumnya pada organisasi yang pernah diikutinya. Maka dari itu sumber daya manusia merupakan faktor penting dalam sebuah organisasi.

Organisasi merupakan suatu sistem yang saling mempengaruhi satu sama lain, apabila salah satu dari sub sistem tersebut rusak, maka akan mempengaruhi sub-sub sistim yang lain (Ansen \& Norman, 2016). Sistim tersebut dapat berjalan dengan semestinya jika individu-individu yang ada di dalamnya berkewajiban mengaturnya yang berarti selama anggota atau individunya masih suka dan melaksanakan tanggung jawab sebagaimana mestinya maka organisasi tersebut akan berjalan dengan baik.

Sumber daya manusia (pegawai) merupakan unsur yang strategis dalam menentukan sehat tidaknya suatu organisasi. Pengembangan sumber daya manusia yang terencana dan berkelanjutan merupakan kebutuhan yang mutlak terutama untuk masa depan organisasi. Dalam kondisi lingkungan tersebut, manajemen dituntut untuk mengembangkan cara baru untuk mempertahankan pegawai pada produktivitas tinggi serta mengembangkan potensinya agar memberikan kontribusi maksimal pada masyarakat. Masalah sumber daya manusia yang kelihatannya hanya merupakan masalah intern dari suatu organisasi sesungguhnya mempunyai hubungan yang kuat dengan masyarakat luas sebagai pelayanan publik yang diukur dari kinerja.

Manajemen sumber daya manusia merupakan sarana untuk meningkatkan kualitas manusia dengan memperbaiki sumber daya manusia, meningkatkan kinerja dan hasil organisasi, sehingga dapat mewujudkan pegawai yang memiliki disiplin dan kinerja yang tinggi sehingga diperlukan pula peran yang besar dari pimpinan organisasi (Gomes \& Cardoso, 2005). Dalam meningkatkan kinerja pegawai diperlukan analisis terhadap faktor-faktor yang mempengaruhinya dengan memperhatikan kebutuhan dari para pegawai, diantaranya adalah terbentuknya budaya organisasi yang baik dan terkoordinasi.

Menurut (Tika, 2006), budaya adalah suatu pola asumsi dasar yang diciptakan, ditemukan atau dikembangkan oleh kelompok tertentu sebagai pembelajaran untuk mengatasi masalah adaptasi eksternal dan integrasi internal yang resmi dan terlaksana dengan baik dan oleh karena itu diajarkan atau diwariskan kepada anggota-anggota baru sebagai cara yang tepat memahami, memikirkan, dan merasakan terkait dengan masalah-masalah tersebut. Budaya organisasi memberikan identitas bagi para anggota 
organisasi dan membangkitkan komitmen terhadap keyakinan dan nilai yang lebih besar dari dirinya sendiri. Meskipun ide-ide ini telah menjadi bagian budaya itu sendiri yang bisa datang di manapun organisasi itu berada. Fungsi budaya dalam organisasi untuk menghubungkan para anggotanya sehingga mereka tahu bagaimana berinteraksi satu sama lain. Budaya organisasi dapat membantu kinerja pegawai, karena menciptakan suatu tingkatan motivasi yang besar bagi pegawai untuk memberikan kemampuan terbaiknya dalam memanfaatkan kesempatan yang diberikan oleh organisasinya.

Budaya organisasi juga mengandung nilai-nilai yang harus dipahami, dijiwai, dan dipraktikan bersama oleh semua individu atau kelompok yang terlibat didalamnya. Adanya nilai-nilai ini akan membuat pegawai merasa nyaman bekerja, memiliki komitmen dan kesetiaan serta membuat pegawai berusaha lebih keras untuk meningkatkan kinerja pegawai yang kompetitif.

Budaya organisasi perlu dimiliki oleh instansi pemerintah agar pegawai memiliki nilai-nilai, norma, acuan pedoman yang harus dilaksanakan. Bila setiap organisasi mempunyai budaya yang kuat artinya seluruh pegawai memiliki satu persepsi yang sama dalam mencapai tujuan organisasi. Kesatuan persepsi ini didasarkan pada kesamaan nilai yang diyakini serta norma yang dijungjung tinggi pada pola perilaku yang ditaati. Nilai dan keyakinan tersebut akan diwujudkan melalui perilaku keseharian pegawai dalam bekerja.

Kinerja adalah sejauh mana seseorang telah memainkan baginya dalam melaksanakan strategi organisasi, baik dalam mencapai sasaran khusus yang berhubungan dengan peran perorangan dan atau dengan memperlihatkan kompetensi yang dinyatakan relevan bagi organisasi (Riniwati, 2011). Kinerja mempunyai arti penting bagi pegawai, adanya penilaian kinerja berarti pegawai mendapat perhatian dari atasan, disamping itu akan menambah semangat kerja pegawai karena dengan penilaian kinerja ini memungkinkan pegawai yang berprestasi dipromosikan, dikembangkan dan diberi penghargaan atas prestasi, sebaliknya pegawai yang tidak berprestasi mungkin akan didemosikan atau diturunkan jabatannya.

Kesulitan mengukur kinerja organisasi pelayanan publik karena tujuan dan misi organisasi publik seringkali tidak hanya sangat kabur akan tetapi juga bersifat multidimensional karena stakeholders dari organisasi publik memiliki kepentingan yang berbeda satu dengan lainnya sehingga ukuran kinerja organisasi publik di mata stakeholders juga berbeda-beda.

Pengukuran kinerja organisasi perlu dilakukan dalam memastikan pemahaman para pelaksana dan mengukur pencapaian prestasi, memastikan tercapainya skema prestasi yang disepakati, memonitor dan mengevaluasi kinerja dengan perbandingan antara skema kerja dan pelaksanaan, memberikan penghargaan maupun hukuman yang obyektif atas prestasi pelaksanaan yang telah diukur sesuai sistem pengukuran yang telah disepakati, menjadikan sebagai alat komunikasi antara pegawai dan pimpinan dalam upaya memperbaiki kinerja organisasi, memastikan bahwa pengambilan keputusan dilakukan secara obyektif dan mengungkapkan permasalahan yang terjadi. 
Kinerja instansi pemerintahan sangat ditentukan oleh kinerja pegawai yang menjadi ujung tombak organisasi itu. Kesadaran para pegawai ataupun pimpinannya akan pengaruh positif budaya organisasi terhadap produktivitas organisasi akan memberikan motivasi yang kuat untuk mempertahankan, memelihara, dan mengembangankan budaya organisasi yang dimiliki, sehingga merupakan daya dorong yang kuat untuk kemajuan organisasi.

Dinas Sosial Provinsi Maluku merupakan dari satuan tatanan pemerintah yang memegang peran dalam menyelenggarakan pembangunan bidang kesejahteraan sosial di Indonesia pada umumnya dan di Kota Ambon pada khususnya yaitu sebagai fasilitator serta sebagai dinamisator. Dinas sosial bertindak mewakili kepentingan serta melayani seluruh masyarakat dalam bidang kesejahteraan sosial sehingga dalam menjalankan peran tersebut, Dinas Sosial Provinsi Maluku berkewajiban untuk meningkatkan manajemen pemerintahan yang lebih efisiensi, efektif, bersih dan berorientasi pada hasil.

Dinas Sosial Provinsi Maluku dalam meningkatkan pelaksanaan manajemen pemerintah yang efisien, efektif, bersih, akuntabel serta berorientasi pada hasil memerlukan langkah-langkah kebijakan yang terarah pada perubahan kelembagaan dan sistem ketatalaksanaan, kualitas sumber daya manusia aparatur, dan sistem pengawasan dan pemeriksaan yang efektif. Unit-unit kerja yang ada pada Dinas Sosial Provinsi Maluku karena itu perlu menyusun Laporan Akuntabilitas Kinerja Instansi Pemerintah (LAKIP) yang disusun sebagai perwujudan pertanggungjawaban Dinas Sosial Provinsi Maluku selaku pengelola sumber daya yang tersedia untuk melaksanakan program dan kegiatan sesuai dengan visi dan misi Dinas Sosial Provinsi Maluku.

Perkembangan situasi dan kondisi pemerintah saat ini yang mengalami perubahan membuat kinerja sumber daya aparatur pemerintah menjadi buruk yaitu dengan rendahnya kinerja instansi pemerintah termasuk Dinas Sosial Provinsi Maluku. Persoalan kinerja inilah yang menjadi sumber kesinisan bagi masyarakat yang berurusan dengan birokrasi. Banyaknya keluhan yang didapat dari pengguna jasa yang menyatakan bahwa kinerja organisasi publik adalah suatu proses keterlambatan administrasi dan kurang efisien serta yang terlihat aparatur pemerintah, yaitu Pegawai Dinas Sosial Provinsi Maluku yang tidak memiliki inisiatif dan tidak transparan karena berpatokan terhadap hal-hal yang tertulis, malas-malasan, takut kepada atasan, kurang disiplin sampai ketidak mampuannya dalam menjalankan tugas yang diberikan kepadanya.

Berdasarkan hasil observasi awal dan wawancara dengan beberapa pegawai kantor Dinas Sosial Provinsi Maluku dapat diketahui masih ada yang tidak menyelesaikan pekerjaan tepat waktunya, disisi lain kinerja pegawaipun sering menjadi masalah dalam mencapai target organisasi karena beberapa faktor pribadi dan budaya organisasi di Dinas Sosial Provinsi Maluku kurang optimal, hal ini dapat dilihat dari beberapa indikasi yaitu :a). Kurang memiliki kompetensi, b). Kurangnya kemampuan untuk mengembangkan diri, serta memberi keteladanan dan menjaga komitmen, namun prakteknya masih terlihat pegawai yang kurang disiplin dan konsistensi terhadap aturan 
yang berlaku. c). Kurang adanya kepercayaan diri dalam berkomunikasi,.d). Kurang adanya kemampuan mengembangkan diri dalam organisasi terhadap perilaku para pegawai dalam melaksanakan tugasnya dengan menggunakan peraturan-peraturan yang ditetapkan demi kelancaran organisasi.Budaya organisasi yang belum maksimal berpengaruh terhadap kinerja pegawai, hal ini ditandai dengan indikasi-indikasi sebagai berikut :a). Kurang memiliki kesetiaan yang sungguh-sungguh dalam melaksanakan tugas yang diberikan. b). Penyelesaian pekerjaan yang diberikan oleh pimpinan tidak diselesaikan secara bersama-sama.c). Pegawai kurang komitmen terhadap waktu dalam menyelesaikan pekerjaan. d). Kurang adanya kerjasama yang baik antara pegawai satu dengan pegawai lainnya.

\section{Metode Penelitian}

Metode penelitian yang dipakai dalam penelitian ini adalah penelitian assosiatif yang bertujuan untuk mengetahui pengaruh antara dua variabel atau lebih (Sugiyono, 2016).

Adapun teknik analisa data dalam penelitian ini menggunakan teknik kuantitatif yang digunakan untuk menguji hubungan variabel bebas dengan variabel terikat. Adapun metode statistik yang digunakan adalah : analisa statistik Product Moment (Sunarto, 2010), dengan rumus sebagai berikut.

$$
\mathrm{r}_{\mathrm{xy}}=\frac{n\left(\sum X Y\right)-\left(\sum X\right) \cdot\left(\sum Y\right)}{\sqrt{\left\{n \sum X^{2}-\left(\sum X\right)^{2}\right\}\left\{n \sum Y^{2}-\left(\sum Y\right)^{2}\right\}}}
$$

Dimana :

Rxy = Koefisien korelasi

$\mathrm{X} \quad=$ Skor dalam distribusi variabel $\mathrm{X}$

$\mathrm{Y} \quad=$ Skor dalam distribusi variabel $\mathrm{Y}$

$\mathrm{n} \quad=$ Banyaknya pasangan skor $\mathrm{X}$ dan $\mathrm{Y}$

Kemudian untuk mencari keberartian hubungan antara kedua variabel pokok, maka hasil korelasi product moment tersebut diuji dengan Uji Signifikansi dengan rumusan sebagai berikut :

$$
\mathrm{t}-\text { test }=\frac{r \sqrt{N-2}}{\sqrt{1-r^{2}}}
$$

Dimana: $\mathrm{t}=$ Nilai $\mathrm{t}$

$$
\begin{aligned}
& \mathrm{r}=\text { Nilai Koefisien Korelasi } \\
& \mathrm{n}=\text { Jumlah Sampel. }
\end{aligned}
$$

Untuk mempermudah melihat hubungan korelasi antara variabel $\mathrm{x}$ dan $\mathrm{y}$, maka penulis membuat tabel pedoman interprestasi koefisien sebagai berikut : 
Tabel 1

Pedoman Untuk Memberikan Interpretasi Koefisien Korelasi

\begin{tabular}{cl}
\hline Interval Koefisien & \multicolumn{1}{c}{ Tingkat Hubungan } \\
\hline $0,000-0,199$ & Sangat Rendah / Sangat Lemah \\
\hline $0,200-0,399$ & Rendah / Lemah \\
\hline $0,400-0,599$ & Sedang \\
\hline $0,600-0,799$ & Kuat \\
\hline $0,800-1,000$ & Sangat Kuat \\
\hline
\end{tabular}

Sumber : (Sugiyono, 2016)

\section{Hasil dan Pembahasan}

1. Distribusi jawaban responden tentang Budaya organisasi

Berdasarkan pertanyaan-pertanyaan yang diajukan kepada keseluruhan responden dalam hubungannya dengan kedua variabel pokok tersebut, maka akan dimasukkan kedalam matriks kerja untuk memperhitungkan korelasi secara rinci bagi masingmasing indikator yang dapat dilihat melalui tabel berikut :

Tabel 2

Distribusi Jawaban Responden Tentang Budaya Organisasi

\begin{tabular}{|c|c|c|c|c|}
\hline \multirow[b]{2}{*}{ No } & \multirow[b]{2}{*}{ Indikator } & \multicolumn{2}{|c|}{ Distribusi Jawaban } & \multirow[b]{2}{*}{ Ket } \\
\hline & & $\mathrm{F}$ & $\%$ & \\
\hline 1. & $\begin{array}{l}\text { Pimpinan mengarahkan dengan jelas } \\
\text { sasaran dan harapan yang diinginkan, } \\
\text { kepada pegawai untuk pencapaian } \\
\text { tujuan organisasi yang tercantum dalam } \\
\text { visi dan misi organisasi }\end{array}$ & & & \\
\hline & a. Sangat setuju & 55 & 71 & \\
\hline & b. Setuju & 22 & 29 & \\
\hline & c. Ragu-ragu & 0 & 0 & \\
\hline & d. Tidak setuju & 0 & 0 & \\
\hline & e. Sangat setuju & 0 & 0 & $\mathrm{n}=77$ \\
\hline
\end{tabular}

2. Apabia diberikan tugas, saya berusaha menyelesaikan dengan tepat waktu
a. Sangat setuju
$53 \quad 69$
b. Setuju

$16 \quad 21$
c. Ragu-ragu

$8 \quad 10$
d. Tidak setuju

$0 \quad 0$
e. Sangat tidak setuju

$0 \quad 0$

3 Jika timbul permasalahan di tempat kerja selalu diselesaikan bersama-sama
a. Sangat setuju
$50 \quad 65$
b. Setuju

$20 \quad 26$
c. Ragu-ragu
$7 \quad 9$
d. Tidak setuju
$0 \quad 0$ 

e. Sangat tidak setuju
0
0

4. Adanya pengawasan dari pimpinan terhadap para pegawai dengan menggunakan peraturan-peraturan yang telah ditetapkan demi kelancaran organisasi.
a. Sangat setuju
$42 \quad 55$
b. Setuju
$25 \quad 32$
c. Ragu-ragu
$10 \quad 13$
d. Tidak setuju

$0 \quad 0$
e. Saangat Tidak Setuju
0
0

Sumber : Hasil Penelitian 2021

Dari tabel 2 di atas terlihat dari 77 responden yang menjawab dapat dijelaskan bahwa sebanyak 55 orang responden $(71 \%)$ mengatakan sangat setuju pimpinan mengarahkan dengan jelas sasaran dan harapan yang diinginkan kepada pegawai untuk pencapaian tujuan organisasi yang tercantum dalam visi dan misi organisasi, sebanyak 22 orang responden $(29 \%)$ mengatakan setuju.

Responden yang mengatakan sangat setuju apabila diberikan tugas saya berusaha menyelesaikan dengan tepat waktu sebanyak 53 orang responden (69\%) yang mengatakan setuju sebanyak 16 orang responden $(21 \%)$, sebanyak 8 orang responden $(10 \%)$ mengatakan ragu-ragu.

50 orang responden (65\%) mengatakan bahwa sangat setuju jika timbul permasalahan ditempat kerja selalu diselesaikan bersama-sama, 20 orang responden (26 $\%)$ mengatakan setuju, yang menjawab ragu-ragu, sebanyak 7 orang responden (9\%).

Sebanyak 42 orang responden (55\%) mengatakan sangat setuju adanya pengawasan dari pimpinan terhadap para pegawai dengan menggunakan peraturanperaturan yang telah ditetapkan demi kelancaran organisasi, 25 orang responden (32\%) mengatakan setuju, sedangkan 10 orang responden (13\%) mengatakan ragu-ragu.

Data yang berhubungan dengan budaya organisasi selanjutnya akan dikonkritkan dalam bentuk skor riil seperti yang terlihat pada tabel sebagai berikut :

Tabel 3

Skor Tentang Budaya Organisasi

\begin{tabular}{|c|c|c|c|c|c|}
\hline \multirow{2}{*}{ No } & \multicolumn{4}{|c|}{ Skor Jawaban Responden } & \multirow{2}{*}{ Total } \\
\hline & X1 & $\mathrm{X} 2$ & X3 & $\mathrm{X4}$ & \\
\hline 1 & 2 & 3 & 4 & 5 & 6 \\
\hline 1 & 5 & 4 & 5 & 5 & 19 \\
\hline 2 & 5 & 5 & 5 & 4 & 19 \\
\hline 3 & 5 & 5 & 5 & 5 & 20 \\
\hline 4 & 5 & 5 & 4 & 5 & 19 \\
\hline 5 & 5 & 5 & 5 & 5 & 20 \\
\hline 6 & 5 & 5 & 5 & 4 & 19 \\
\hline
\end{tabular}




\begin{tabular}{|c|c|c|c|c|c|}
\hline \multirow{2}{*}{ No } & \multicolumn{4}{|c|}{ Skor Jawaban Responden } & \multirow{2}{*}{ Total } \\
\hline & $\mathbf{X 1}$ & $\mathbf{X 2}$ & X3 & $\mathbf{X 4}$ & \\
\hline 7 & 5 & 5 & 5 & 5 & 20 \\
\hline 8 & 4 & 5 & 5 & 5 & 19 \\
\hline 9 & 5 & 4 & 5 & 4 & 18 \\
\hline 10 & 5 & 5 & 5 & 5 & 20 \\
\hline 11 & 5 & 5 & 5 & 3 & 18 \\
\hline 12 & 5 & 5 & 5 & 5 & 20 \\
\hline 13 & 5 & 5 & 3 & 5 & 18 \\
\hline 14 & 5 & 5 & 5 & 5 & 20 \\
\hline 15 & 5 & 5 & 5 & 3 & 18 \\
\hline 16 & 4 & 5 & 5 & 5 & 19 \\
\hline 17 & 5 & 4 & 5 & 5 & 19 \\
\hline 18 & 5 & 5 & 5 & 5 & 20 \\
\hline 19 & 5 & 5 & 5 & 4 & 19 \\
\hline 20 & 5 & 5 & 4 & 5 & 19 \\
\hline 21 & 5 & 5 & 5 & 5 & 20 \\
\hline 22 & 5 & 5 & 5 & 3 & 18 \\
\hline 23 & 4 & 5 & 5 & 4 & 18 \\
\hline 24 & 5 & 4 & 5 & 4 & 18 \\
\hline 25 & 5 & 5 & 5 & 5 & 20 \\
\hline 26 & 5 & 5 & 5 & 5 & 20 \\
\hline 27 & 5 & 3 & 4 & 4 & 16 \\
\hline 28 & 5 & 5 & 5 & 5 & 20 \\
\hline 29 & 4 & 5 & 5 & 5 & 19 \\
\hline 30 & 5 & 5 & 5 & 5 & 20 \\
\hline 31 & 5 & 5 & 4 & 5 & 19 \\
\hline 32 & 5 & 3 & 5 & 5 & 18 \\
\hline 33 & 4 & 5 & 5 & 4 & 18 \\
\hline 34 & 5 & 5 & 5 & 5 & 20 \\
\hline 35 & 5 & 5 & 5 & 5 & 20 \\
\hline 36 & 5 & 4 & 4 & 5 & 18 \\
\hline 37 & 5 & 5 & 5 & 5 & 19 \\
\hline 38 & 4 & 5 & 5 & 5 & 19 \\
\hline 39 & 5 & 5 & 5 & 5 & 20 \\
\hline 40 & 5 & 5 & 5 & 3 & 18 \\
\hline 41 & 5 & 5 & 5 & 5 & 20 \\
\hline 42 & 5 & 5 & 4 & 5 & 19 \\
\hline 43 & 5 & 5 & 5 & 3 & 18 \\
\hline 44 & 5 & 5 & 5 & 5 & 20 \\
\hline 45 & 4 & 5 & 5 & 4 & 18 \\
\hline 46 & 5 & 5 & 4 & 5 & 19 \\
\hline
\end{tabular}


Pengaruh Budaya Organisasi terhadap Kinerja Pegawai pada Dinas Sosial Provinsi Maluku

\begin{tabular}{|c|c|c|c|c|c|}
\hline \multirow{2}{*}{ No } & \multicolumn{4}{|c|}{ Skor Jawaban Responden } & \multirow{2}{*}{ Tota } \\
\hline & $\mathbf{X 1}$ & $\mathbf{X 2}$ & X3 & $\mathbf{X 4}$ & \\
\hline 47 & 5 & 5 & 5 & 4 & 19 \\
\hline 48 & 4 & 5 & 5 & 5 & 19 \\
\hline 49 & 4 & 5 & 5 & 5 & 19 \\
\hline 50 & 5 & 5 & 4 & 5 & 19 \\
\hline 51 & 4 & 5 & 5 & 5 & 19 \\
\hline 52 & 4 & 5 & 5 & 5 & 19 \\
\hline 53 & 4 & 5 & 5 & 5 & 19 \\
\hline 54 & 5 & 5 & 5 & 4 & 19 \\
\hline 55 & 4 & 5 & 5 & 4 & 18 \\
\hline 56 & 5 & 3 & 4 & 4 & 16 \\
\hline 57 & 5 & 3 & 4 & 4 & 16 \\
\hline 58 & 5 & 4 & 3 & 3 & 15 \\
\hline 59 & 5 & 4 & 3 & 3 & 15 \\
\hline 60 & 5 & 4 & 4 & 4 & 17 \\
\hline 61 & 5 & 4 & 4 & 4 & 17 \\
\hline 62 & 5 & 4 & 4 & 4 & 17 \\
\hline 63 & 5 & 4 & 4 & 4 & 17 \\
\hline 64 & 5 & 4 & 4 & 4 & 17 \\
\hline 65 & 5 & 4 & 4 & 4 & 17 \\
\hline 66 & 5 & 3 & 5 & 5 & 18 \\
\hline 67 & 5 & 5 & 5 & 5 & 20 \\
\hline 68 & 4 & 5 & 5 & 5 & 19 \\
\hline 69 & 4 & 3 & 5 & 5 & 17 \\
\hline 70 & 4 & 4 & 3 & 4 & 15 \\
\hline 71 & 4 & 4 & 3 & 4 & 15 \\
\hline 72 & 4 & 3 & 3 & 4 & 14 \\
\hline 73 & 4 & 3 & 3 & 4 & 14 \\
\hline 74 & 4 & 4 & 4 & 3 & 15 \\
\hline 75 & 4 & 4 & 4 & 3 & 15 \\
\hline 76 & 4 & 5 & 4 & 5 & 18 \\
\hline \multirow[t]{2}{*}{77} & 4 & 5 & 4 & 3 & 16 \\
\hline & & & & & 1386 \\
\hline
\end{tabular}

Keterangan :

$\mathrm{X} 1$ = Indikator Variabel $\mathrm{X}$ pertama

$\mathrm{X} 2$ = Indikator Variabel $\mathrm{X}$ kedua

$\mathrm{X} 3$ = Indikator Variabel $\mathrm{X}$ ketiga 


$$
\mathrm{X} 4=\text { Indikator Variabel } \mathrm{X} \text { keempat }
$$

Untuk mengetahui tanggapan beberapa responden tentang indikator-indikator tersebut diatas diajukan beberapa daftar pertanyaan kepada responden terkait dengan kinerja pegawai seperti terlihat dalam tabel berikut :

Tabel 4

Distribusi Jawaban Responden Tentang Kinerja Pegawai

\begin{tabular}{llc}
\hline \multirow{2}{*}{ No } & Indikator & \multicolumn{2}{c}{$\begin{array}{c}\text { Distribusi } \\
\text { Jawaban }\end{array}$} \\
\cline { 2 - 2 } & Ket & F $\%$ \\
\hline
\end{tabular}

1. Memiliki tingkat kompetensi yang tinggi dan berusaha untuk mengikuti perkembangan yang ada
a. Sangat setuju
$54 \quad 70$
b. Setuju
$23 \quad 30$
c. Ragu-ragu
$0 \quad 0$
d. Tidak setuju
$0 \quad 0$
e. Sangat setuju

$0 \quad 0$

2. Memiliki pengetahuan yang luas yang dapat membantu orang lain dalam pengambilan keputusan
a. Sangat setuju
$54 \quad 70$
b. Setuju
$23 \quad 30$
c. Ragu-ragu
$0 \quad 0$
d. Tidak setuju
$0 \quad 0$
e. Sangat tidak setuju
$0 \quad 0$

3. Memiliki kepercayaan diri dan kemampuan yang tinggi dalam membuat keputusan yang baik.
a. Sangat setuju
b. Setuju
$21 \quad 27$
c. Ragu-ragu
$11 \quad 14$
d. Tidak setuju
$0 \quad 0$
e. Sangat tidak setuju
$0 \quad 0$$$
\mathrm{n}=77
$$

4. Mampu memilih dan melihat masalah dari sudut pandang yang berbeda dengan orang lain.
a. Sangat setuju
$50 \quad 65$
b. Setuju
$12 \quad 16$
c. Ragu-ragu
$15 \quad 19$
d. Tidak setuju

$0 \quad 0$
e. Sangat tidak setuju

$0 \quad 0$

Sumber : Hasil Penelitian 2020 
Berdasarkan tabel 9 tersebut diatas dapat dilihat tanggapan responden sebagai berikut:

Dari tabel tersebut di atas dijelaskan bahwa sebanyak 54 orang responden (70 \%) mengatakan sangat setuju memiliki tingkat kompetensi yang tinggi dan berusaha untuk mengikuti perkembangan yang ada, sebanyak 23 orang responden (30\%) mengatakan setuju.

Sebanyak 54 orang responden $(70 \%)$ mengatakan sangat setuju memiliki pengetahuan yang luas yang dapat membantu orang lain dalam pengambilan keputusan, sebanyak 23 orang responden (30\%) mengatakan setuju.

Sebanyak 45 orang responden (53\%) mengatakan sangat setuju memiliki kepercayaan diri dan kemampuan yang tinggi dalam membuat keputusan yang baik, sebanyak 21 orang responden $(27 \%)$ dan yang mengatakan ragu-ragu sebanyak 11 orang responden $(14 \%)$

Sebanyak 50 orang responden (65\%) mengatakan sangat setuju mampu memilih dan melihat masalah dari sudut pandang yang berbeda dengan orang lain, sebanyak 12 orang responden (16\%) mengatakan setuju dan mengatakan ragu-ragu sebanyak 15 orang responden (19\%). mampu memilih dan melihat masalah dari sudut pandang yang berbeda dengan orang lain.

Data-data yang berhubungan dengan kinerja pegawai, selanjutnya akan dikonkritkan dalam bentuk skor riil seperti yang terlihat pada tabel berikut :

Tabel 5

Skor Tentang Kinerja Pegawai

\begin{tabular}{|c|c|c|c|c|c|}
\hline \multirow{2}{*}{ No } & \multicolumn{4}{|c|}{ Skor Jawaban Responden } & \multirow{2}{*}{ Total } \\
\hline & Y1 & Y2 & Y3 & Y4 & \\
\hline 1 & 2 & 3 & 4 & 5 & 6 \\
\hline 1 & 5 & 5 & 5 & 3 & 18 \\
\hline 2 & 5 & 5 & 5 & 3 & 18 \\
\hline 3 & 5 & 3 & 4 & 4 & 16 \\
\hline 4 & 5 & 3 & 5 & 5 & 18 \\
\hline 5 & 5 & 3 & 5 & 5 & 18 \\
\hline 6 & 5 & 2 & 5 & 4 & 16 \\
\hline 7 & 5 & 3 & 5 & 5 & 18 \\
\hline 8 & 5 & 3 & 5 & 5 & 18 \\
\hline 9 & 5 & 3 & 5 & 5 & 18 \\
\hline 10 & 4 & 3 & 5 & 5 & 17 \\
\hline 11 & 5 & 3 & 5 & 5 & 18 \\
\hline 12 & 5 & 3 & 5 & 3 & 16 \\
\hline 13 & 5 & 3 & 3 & 5 & 16 \\
\hline 14 & 5 & 3 & 5 & 5 & 15 \\
\hline 15 & 5 & 2 & 5 & 3 & 15 \\
\hline 16 & 5 & 3 & 5 & 5 & 18 \\
\hline 17 & 5 & 3 & 3 & 5 & 16 \\
\hline
\end{tabular}


Montgomery Warbal, Bernard C. Renyut, Selvia F.G. Renyut

\begin{tabular}{|c|c|c|c|c|c|}
\hline \multirow{2}{*}{ No } & \multicolumn{4}{|c|}{ Skor Jawaban Responden } & \multirow{2}{*}{ Tota } \\
\hline & Y1 & Y2 & Y3 & Y4 & \\
\hline 18 & 5 & 3 & 5 & 5 & 18 \\
\hline 19 & 5 & 3 & 4 & 5 & 17 \\
\hline 20 & 5 & 3 & 5 & 5 & 18 \\
\hline 21 & 5 & 3 & 5 & 5 & 18 \\
\hline 22 & 5 & 3 & 5 & 3 & 16 \\
\hline 23 & 5 & 2 & 5 & 3 & 15 \\
\hline 24 & 5 & 3 & 5 & 5 & 18 \\
\hline 25 & 5 & 3 & 5 & 5 & 18 \\
\hline 26 & 5 & 3 & 5 & 5 & 18 \\
\hline 27 & 4 & 3 & 4 & 3 & 14 \\
\hline 28 & 5 & 3 & 5 & 5 & 18 \\
\hline 29 & 5 & 3 & 5 & 4 & 17 \\
\hline 30 & 5 & 3 & 5 & 5 & 18 \\
\hline 31 & 5 & 3 & 5 & 5 & 18 \\
\hline 32 & 5 & 3 & 5 & 5 & 18 \\
\hline 33 & 5 & 3 & 4 & 5 & 17 \\
\hline 34 & 5 & 3 & 5 & 5 & 18 \\
\hline 35 & 5 & 3 & 4 & 5 & 17 \\
\hline 36 & 5 & 3 & 5 & 3 & 16 \\
\hline 37 & 5 & 5 & 5 & 5 & 20 \\
\hline 38 & 5 & 5 & 5 & 5 & 20 \\
\hline 39 & 5 & 5 & 5 & 5 & 20 \\
\hline 40 & 5 & 5 & 5 & 5 & 20 \\
\hline 41 & 5 & 5 & 5 & 3 & 18 \\
\hline 42 & 5 & 5 & 3 & 5 & 18 \\
\hline 43 & 4 & 5 & 5 & 3 & 17 \\
\hline 44 & 5 & 5 & 5 & 5 & 20 \\
\hline 45 & 4 & 5 & 5 & 3 & 17 \\
\hline 46 & 5 & 5 & 5 & 5 & 20 \\
\hline 47 & 5 & 5 & 5 & 5 & 20 \\
\hline 48 & 5 & 4 & 5 & 5 & 19 \\
\hline 49 & 5 & 5 & 4 & 5 & 19 \\
\hline 50 & 5 & 5 & 4 & 4 & 18 \\
\hline 51 & 5 & 5 & 5 & 4 & 19 \\
\hline 52 & 5 & 5 & 5 & 5 & 20 \\
\hline 53 & 5 & 5 & 5 & 5 & 20 \\
\hline 54 & 5 & 5 & 5 & 4 & 19 \\
\hline 55 & 5 & 5 & 4 & 3 & 17 \\
\hline 56 & 5 & 5 & 4 & 5 & 19 \\
\hline 57 & 4 & 4 & 5 & 3 & 16 \\
\hline 58 & 4 & 4 & 3 & 5 & 16 \\
\hline 59 & 4 & 4 & 3 & 5 & 16 \\
\hline 60 & 4 & 4 & 4 & 4 & 16 \\
\hline 61 & 4 & 4 & 4 & 4 & 16 \\
\hline
\end{tabular}




\begin{tabular}{|c|c|c|c|c|c|}
\hline \multirow{2}{*}{ No } & \multicolumn{4}{|c|}{ Skor Jawaban Responden } & \multirow{2}{*}{ Tota } \\
\hline & Y1 & Y2 & Y3 & Y4 & \\
\hline 62 & 4 & 4 & 4 & 4 & 16 \\
\hline 63 & 4 & 4 & 4 & 4 & 16 \\
\hline 64 & 4 & 4 & 4 & 4 & 16 \\
\hline 65 & 4 & 4 & 4 & 4 & 16 \\
\hline 66 & 5 & 5 & 5 & 5 & 20 \\
\hline 67 & 4 & 4 & 5 & 5 & 18 \\
\hline 68 & 5 & 5 & 5 & 5 & 20 \\
\hline 69 & 4 & 4 & 5 & 5 & 18 \\
\hline 70 & 4 & 4 & 5 & 5 & 18 \\
\hline 71 & 4 & 4 & 5 & 5 & 18 \\
\hline 72 & 4 & 4 & 4 & 5 & 17 \\
\hline 73 & 4 & 4 & 4 & 5 & 17 \\
\hline 74 & 4 & 4 & 4 & 4 & 16 \\
\hline 75 & 4 & 4 & 4 & 4 & 16 \\
\hline 76 & 4 & 4 & 4 & 3 & 15 \\
\hline \multirow[t]{2}{*}{77} & 4 & 4 & 4 & 3 & 15 \\
\hline & & & & & 1348 \\
\hline
\end{tabular}

Sumber : Hasil Analisis 2020

Keterangan :

$$
\begin{aligned}
& \mathrm{Y} 1=\text { Indikator Variabel Y pertama } \\
& \mathrm{Y} 2=\text { Indikator Variabel Y kedua } \\
& \mathrm{Y} 3=\text { Indikator Variabel Y ketiga } \\
& \mathrm{Y} 4=\text { Indikator Variabel Y keempat }
\end{aligned}
$$

Data pada tabel variabel X (Budaya Organisasi) dan variabel Y (Kinerja Pegawai) kemudian didistribusikan ke tabel perhitungan korelasi product moment antara lain seperti terlihat pada tabel berikut ini :

Tabel 6

Perhitungan Korelasi Product Moment

\begin{tabular}{cccccc}
\hline NO & $\sum \mathbf{X}$ & $\sum \mathbf{Y}$ & $\sum \mathbf{X}^{\mathbf{2}}$ & $\sum \mathbf{Y}^{\mathbf{2}}$ & $\sum \mathbf{X Y}$ \\
\hline $\mathbf{1}$ & $\mathbf{2}$ & $\mathbf{3}$ & $\mathbf{4}$ & $\mathbf{5}$ & $\mathbf{6}$ \\
\hline 1 & 19 & 18 & 361 & 324 & 342 \\
\hline 2 & 19 & 18 & 361 & 324 & 342 \\
\hline 3 & 20 & 16 & 400 & 256 & 320 \\
\hline 4 & 19 & 18 & 361 & 324 & 342 \\
\hline 5 & 20 & 18 & 400 & 324 & 360 \\
\hline 6 & 19 & 16 & 361 & 256 & 304 \\
\hline 7 & 20 & 18 & 400 & 324 & 360 \\
\hline 8 & 19 & 18 & 400 & 324 & 342 \\
\hline 9 & 18 & 18 & 324 & 324 & 324 \\
\hline 10 & 20 & 17 & 400 & 289 & 340 \\
\hline 11 & 18 & 18 & 324 & 324 & 324 \\
\hline 12 & 20 & 16 & 400 & 256 & 320 \\
\hline
\end{tabular}




\begin{tabular}{cccccc}
\hline NO & $\sum \mathbf{X}$ & $\sum \mathbf{Y}$ & $\sum \mathbf{X}^{\mathbf{2}}$ & $\sum \mathbf{Y}^{\mathbf{2}}$ & $\sum \mathbf{X Y}$ \\
\hline $\mathbf{1}$ & $\mathbf{2}$ & $\mathbf{3}$ & $\mathbf{4}$ & $\mathbf{5}$ & $\mathbf{6}$ \\
\hline 13 & 18 & 16 & 324 & 256 & 288 \\
\hline 14 & 20 & 15 & 400 & 225 & 300 \\
\hline 15 & 18 & 15 & 324 & 225 & 270 \\
\hline 16 & 19 & 18 & 361 & 324 & 342 \\
\hline 17 & 19 & 16 & 361 & 256 & 304 \\
\hline 18 & 20 & 18 & 400 & 324 & 360 \\
\hline 19 & 19 & 17 & 361 & 289 & 323 \\
\hline 20 & 19 & 18 & 361 & 324 & 342 \\
\hline 21 & 20 & 18 & 400 & 324 & 360 \\
\hline 22 & 18 & 16 & 324 & 256 & 288 \\
\hline 23 & 18 & 15 & 324 & 225 & 270 \\
\hline 24 & 18 & 18 & 324 & 324 & 324 \\
\hline 25 & 20 & 18 & 400 & 324 & 360 \\
\hline 26 & 20 & 18 & 400 & 324 & 360 \\
\hline 27 & 16 & 14 & 256 & 196 & 224 \\
\hline 28 & 20 & 18 & 400 & 324 & 260 \\
\hline 29 & 19 & 17 & 361 & 289 & 323 \\
\hline 30 & 20 & 18 & 400 & 324 & 360 \\
\hline 31 & 19 & 18 & 361 & 324 & 342 \\
\hline 32 & 18 & 18 & 324 & 324 & 324 \\
\hline 33 & 18 & 17 & 324 & 289 & 306 \\
\hline 34 & 20 & 18 & 400 & 324 & 360 \\
\hline 35 & 20 & 17 & 400 & 289 & 340 \\
\hline 36 & 18 & 16 & 324 & 256 & 288 \\
\hline 37 & 20 & 20 & 400 & 400 & 400 \\
\hline 38 & 19 & 20 & 361 & 400 & 380 \\
\hline 39 & 20 & 20 & 400 & 400 & 400 \\
\hline 40 & 18 & 20 & 324 & 400 & 360 \\
\hline 41 & 20 & 18 & 400 & 324 & 360 \\
\hline 42 & 19 & 18 & 361 & 324 & 342 \\
\hline 43 & 18 & 17 & 324 & 289 & 306 \\
\hline 44 & 20 & 20 & 400 & 400 & 400 \\
\hline 45 & 18 & 17 & 324 & 289 & 306 \\
\hline 46 & 19 & 20 & 361 & 400 & 380 \\
\hline 47 & 19 & 20 & 361 & 400 & 380 \\
\hline 48 & 19 & 19 & 361 & 361 & 361 \\
\hline 49 & 19 & 19 & 361 & 361 & 361 \\
\hline 50 & 19 & 18 & 361 & 324 & 342 \\
\hline 51 & 19 & 19 & 361 & 361 & 361 \\
\hline 52 & 19 & 20 & 361 & 400 & 380 \\
\hline 53 & 19 & 20 & 361 & 400 & 380 \\
\hline 54 & 19 & 19 & 361 & 361 & 361 \\
\hline 55 & 18 & 17 & 324 & 289 & 306 \\
\hline 56 & 16 & 19 & 256 & 361 & 304 \\
\hline & & & & & \\
\hline
\end{tabular}


Pengaruh Budaya Organisasi terhadap Kinerja Pegawai pada Dinas Sosial Provinsi Maluku

\begin{tabular}{cccccc}
\hline $\mathbf{N O}$ & $\sum \mathbf{X}$ & $\sum \mathbf{Y}$ & $\sum \mathbf{X}^{\mathbf{2}}$ & $\sum \mathbf{Y}^{\mathbf{2}}$ & $\sum \mathbf{X Y}$ \\
\hline $\mathbf{1}$ & $\mathbf{2}$ & $\mathbf{3}$ & $\mathbf{4}$ & $\mathbf{5}$ & $\mathbf{6}$ \\
\hline 57 & 16 & 16 & 256 & 256 & 256 \\
\hline 58 & 15 & 16 & 225 & 256 & 240 \\
\hline 59 & 15 & 16 & 225 & 256 & 240 \\
\hline 60 & 17 & 16 & 289 & 256 & 272 \\
\hline 61 & 17 & 16 & 289 & 256 & 272 \\
\hline 62 & 17 & 16 & 289 & 256 & 272 \\
\hline 63 & 17 & 16 & 289 & 256 & 272 \\
\hline 64 & 17 & 16 & 289 & 361 & 272 \\
\hline 65 & 17 & 16 & 289 & 256 & 272 \\
\hline 66 & 18 & 20 & 324 & 400 & 360 \\
\hline 67 & 20 & 18 & 400 & 324 & 360 \\
\hline 68 & 19 & 20 & 361 & 400 & 380 \\
\hline 69 & 17 & 18 & 289 & 324 & 306 \\
\hline 70 & 15 & 18 & 225 & 324 & 270 \\
\hline 71 & 15 & 18 & 225 & 324 & 270 \\
\hline 72 & 14 & 17 & 196 & 289 & 238 \\
\hline 73 & 14 & 17 & 196 & 289 & 238 \\
\hline 74 & 15 & 16 & 225 & 256 & 240 \\
\hline 75 & 15 & 16 & 225 & 256 & 240 \\
\hline 76 & 18 & 15 & 324 & 225 & 270 \\
\hline 77 & 16 & 15 & 256 & 225 & 240 \\
\hline & 1386 & 1348 & 25240 & 26846 & 24688 \\
\hline
\end{tabular}

Berdasarkan atas data yang ada pada tabel perhitungan di atas, maka kemudian akan dihitung dengan mempergunakan rumus Korelasi Product Moment sebagai berikut:

$$
\begin{gathered}
\mathbf{r}_{\mathrm{xy}}=\frac{n\left(\sum X Y\right)-\left(\sum X\right) \cdot\left(\sum Y\right)}{\sqrt{\left\{n \sum X^{2}-\left(\sum X\right)^{2}\right\}\left\{n \sum Y^{2}-\left(\sum Y\right)^{2}\right\}}} \\
\operatorname{rxy}=\frac{77(24688)-(1386) .(1384)}{\sqrt{\left\{77.25240-1386^{2}\right\}\left\{77.26846-1384^{2}\right\}}} \\
\operatorname{rxy}=\frac{1900976-1868328}{\sqrt{\{1943480-1920996\}\{2067142-1817104\}}} \\
\operatorname{rxy}=\frac{\frac{32648}{\sqrt{\{2484\}\{250038}\}}}{\operatorname{rxy}}=\frac{\sqrt{56218}}{\sqrt{ }}
\end{gathered}
$$$$
32648
$$ 


$$
\begin{aligned}
& \operatorname{rxy}=\frac{74979}{\operatorname{rxy}}=0,435
\end{aligned}
$$

Dari hasil perhitungan tersebut dapatlah diketahui bahwa korelasi antara Budaya Organisasi (X) terhadap Kinerja Pegawai (Y) sebesar 0,435 terdapat hubungan yang sedang karena berada pada rentang 0,400 - 0,599. Sedangkan arah hubungan adalah positif karena nilai $r$ positif artinya jika pengaruh budaya organisasi, maka kinerja baik dan sebaliknya atau apabila terjadi perubahan atau peningkatan sebesar 0,435 pada budaya organisasi, maka terjadi pula perubahan atau peningkatan sebesar 0,435 pada kinerja pegawai.

Untuk mengetahui tingkat signifikan tidaknya kedua variabel tersebut, dapat dilihat pada analisis berikut ini :

$$
\begin{aligned}
\mathrm{t}-\mathrm{test} & =\sqrt{\frac{\mathrm{n}-2}{\mathrm{r}^{2}}} \\
& =\frac{0,435 \sqrt{77-2}}{\sqrt{1-0,435^{2}}} \\
& =\frac{\sqrt{1-435} \frac{\sqrt{75}}{0,435 \times 8,660}}{\sqrt{0,811}} \\
& =\frac{3,767}{0,900} \\
& =4,185
\end{aligned}
$$

Adapun hasil perhitungan menunjukkan nilai t-test sebesar 4,185. Hasil ini akan dibandingkan dengan nilai pada t-tabel. Untuk kesalahan $5 \%$ uji dua pihak dan $\mathrm{dk}=\mathrm{n}-2$ $=75$, maka diperoleh t-tabel $=1,671$. Jadi koefisien korelasi antara budaya organisasi dengan kinerja pegawai sebesar 1,671. Dengan demikian t-hitung lebih besar dari t-tabel $(4,185>1,671)$ berarti bahwa ada pengaruh yang signifikan antara budaya organisasi terhadap kinerja pegawai.

Sedangkan untuk mencari besarnya sumbangan (kontribusi) variabel $\mathrm{X}$ terhadap variabel Y, digunakan rumus : 


$$
\begin{aligned}
\mathrm{KP} & =r^{2} \times 100 \% \\
& =0,435^{2} \times 100 \% \\
& =0,189 \times 100 \% \\
& =18,9 \%
\end{aligned}
$$

Perhitungan tersebut diatas memberikan arti bahwa budaya organisasi memberikan kontribusi terhadap kinerja pegawai pada Dinas Sosial Provinsi Maluku sebesar $18,9 \%$ dan sisanya $81,1 \%$ ditentukan oleh faktor lain yang tidak terdapat dalam penelitian ini.

\section{Pembahasan}

Hasil penelitian ini menunjukkan bahwa budaya organisasi mempunyai pengaruh yang kuat dan signifikan dengan kinerja pegawai pada Dinas Sosial Provinsi Maluku, dengan demikian dapat diinterpretasikan sebagai berikut :

1. Dari tabel distribusi jawaban responden tentang budaya organisasi ada 55 orang (71 \%) mengatakan bahwa pimpinan mengarahkan dengan jelas sasaran dan harapan yang diinginkan, kepada pegawai untuk pencapaian tujuan organisasi yang tercantum dalam visi dan misi organisasi, sedangkan distribusi jawaban responden tentang kinerja pegawai sekitar 54 orang (70\%) mengatakan memiliki tingkat kompetensi yang tinggi dan berusaha untuk mengikuti perkembangan yang ada, memiliki pengetahuan yang luas yang dapat membantu orang lain dalam pengambilan keputusan.

2. Terdapat pengaruh yang sedang antara budaya organisasi dengan kinerja pegawai pada Dinas Sosial Provinsi Maluku, yang berarti bahwa semakin besar nilai variabel budaya organisasi, maka akan semakin besar nilai variabel kinerjanya, dan sebaliknya semakin kecil nilai variabel budaya organisasi, maka akan semakin kecil pula nilai variabel kinerjanya. Hal ini menunjukkan bahwa budaya organisasi merupakan faktor yang berpengaruh terhadap kinerja pegawai.

3. Kinerja pegawai pada Dinas Sosial Provinsi Maluku dari hasil analisa data sebagai akibat dari pengaruh budaya organisasi secara umum dapat ditunjang oleh kesetiaan, prestasi kerja, kedisiplinan dan kerjasama diantara pegawai.

4. Dari hasil analisa statistik menunjukkan bahwa besarnya presentase pengaruh variabel bebas terhadap variabel terikat, artinya jika ingin meningkatkan kinerja pegawai, maka budaya organisasi harus berdasarkan pada inisiatif individu, pengarahan, dukungan manajemen, kontrol, dan besar koefisien diterminasinya adalah 0,435 , hal ini berarti bahwa pengaruh variabel bebas terhadap perubahan variabel terikat adalah $18,9 \%$, sedangkan $81,1 \%$ sisanya dipengaruhi oleh variabel lain selain variabel budaya organisasi yang tidak masuk dalam penelitian ini 


\section{Kesimpulan}

Dari hasil penelitian yang dilakukan pada Dinas Sosial Provinsi Maluku dapat ditarik kesimpulan sebagai berikut :

1. Analisis pengaruh budaya organisasi terhadap kinerja pegawai diperoleh nilai koefisien diterminasinya adalah 0,435 , hal ini berarti bahwa pengaruh variabel bebas terhadap perubahan variabel terikat adalah $18,9 \%$, sedangkan $81,1 \%$ sisanya dipengaruhi oleh faktor lain yang tidak diteliti pada penelitian ini.

2. Korelasi antara pengaruh budaya organisasi terhadap kinerja pegawai Dinas Sosial Provinsi Maluku berdasarkan analisa, maka terdapat pengaruh yang sedang yakni budaya organisasi baik sebesar 4,185 jika dibandingkan dengan tingkat budaya organisasi tidak baik 1,671, sehingga menunjukkan bahwa budaya organisasi berpengaruh signifikan terhadap kinerja pegawai pada Dinas Sosial Provinsi Maluku. Dengan demikian hipotesis tersebut teruji kebenarannya. Dan dapat diketahui bahwa antara budaya organisasi dengan kinerja pegawai berpengaruh signifikan yang sedang dimana semakin baik budaya organisasi, maka semakin meningkat kinerja pegawai. 
Pengaruh Budaya Organisasi terhadap Kinerja Pegawai pada Dinas Sosial Provinsi

Maluku

\section{BIBLIOGRAFI}

Ansen, Yopines, \& Norman, Edwin. (2016). Hambatan Komunikasi Dan Budaya Guna Meningkatkan Produktivitas Kerja. Study \& Management Research, 23. Google Scholar

Gomes, Faustino Cardoso, \& Cardoso, Faustino. (2005). Manajemen Sumber Daya Manusia, Andi Offset, Y ogyakarta. Edisi. Google Scholar

Riniwati, Harsuko. (2011). Mendongkrak Motivasi dan Kinerja: Pendekatan Pemberdayaan SDM. Universitas Brawijaya, Malang. Google Scholar

Sugiyono. (2016). Metode Penelitian Administrasi (Edisi Keti). Bandung: CV. Alfabetha. Google Scholar

Sunarto, H. (2010). Pengantar statistika. Google Scholar

Tika, Pabundu. (2006). Budaya organisasi dan peningkatan kinerja perusahaan. Jakarta: Bumi Aksara. Google Scholar

\section{Copyright holder:}

Montgomery Warbal, Bernard C. Renyut, Selvia F.G. Renyut (2021)

First publication right:

Syntax Literate: Jurnal Ilmiah Indonesia

This article is licensed under:

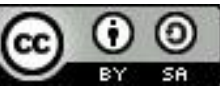

